\title{
Stress Transfer in Microfibrillated Cellulose Reinforced Poly(vinyl alcohol) Composites
}

\author{
Supachok Tanpichai ${ }^{1,2}$, William W Sampson ${ }^{2}$ and Stephen J Eichhorn ${ }^{3}$ \\ ${ }^{1}$ Learning Institute, King Mongkut's University of Technology Thonburi, Pracha-Uthit \\ road, Bangmod, Thung khru, Bangkok, 10140, Thailand \\ ${ }^{2}$ School of Materials, University of Manchester, Manchester, M13 9PL, United Kingdom \\ ${ }^{3}$ College of Engineering, Mathematics and Physical Sciences, University of Exeter, \\ Physics Building, Stocker Road, Exeter, EX4 4QL, United Kingdom \\ supachok.tan@kmutt.ac.th,w.sampson@manchester.ac.uk, s.j.eichhorn@exeter.ac.uk
}

\begin{abstract}
Combined homogenization and sonication treatments of micron-sized lyocell fibres were used to generate microfibrillated celluose (MFC) with fibril diameters of $\sim 350 \mathrm{~nm}$. No further reduction in fibril diameter was observed after 30 minutes treatment. Poly(vinyl alcohol) (PVA) composites reinforced with these fibrils were fabricated using solvent casting and physical and mechanical properties were investigated. The presence of MFC in PVA increased the thermal degradation of the polymer. An increase in both the tensile strength and modulus of the composites was observed for up to $3 \mathrm{wt} . \%$ of fibrils; beyond this point no significant increases were observed. An estimate of $\sim 39 \mathrm{GPa}$ is made for the fibril modulus based on this increase. Stress-transfer between the polymer resin and the fibrils was investigated using Raman spectroscopy. Stress transfer in the composite is shown to be greater than that of a pure network of fibres, indicating a good fibre-matrix bond.
\end{abstract}

\section{Keywords}


A: Nano-structures; B: Stress transfer; C: Micro-mechanics; D: Mechanical testing

\section{Introduction}

The term microfibrillated cellulose (MFC), was introduced in 1983 by Herrick et al. [1] and Turbak et al. [2] to describe high aspect ratio cellulosic fibrils with diameters of 10 $100 \mathrm{~nm}$ and lengths of several tens of microns obtained by high-pressure homogenisation of wood pulp suspensions [1-3]. It has subsequently been established that MFC can be readily prepared using a range of mechanical treatments including grinding, microfluidising, sonication and homogenization [1, 3-9]. Interest in the use of MFC to reinforce a polymer composite has grown over the last decade due to the fibres' high aspect ratio, crystallinity, stiffness and specific surface area $[3,10]$.

The crystal modulus of cellulose has been measured as about $138 \mathrm{GPa}$ using an Xray diffraction method $[11,12]$. A similar value of $143 \mathrm{GPa}$ for the modulus of highly crystalline tunicate cellulose nanowhiskers, obtained using Raman spectroscopy, has also been reported [13]. Values in the range 29-180 GPa have been reported for cellulose fibrils produced from a variety of sources including wood fibres [14, 15], bacterial cellulose [16,17], tunicates [18] and regenerated cellulose [14]. A recent modelling study has placed the modulus of MFC fibrils as low as $65 \mathrm{GPa}$ [19], and some estimates, using Raman spectroscopic methods give values lower still at 29 GPa [15]. MFC has been previously used to prepare composite materials with a large number of polymers such as poly(lactic acid) (PLA) [7, 10], poly(vinyl alcohol) (PVA) [8, 20, 21], polypropylene[20], polyurethane [22], phenol formaldehyde resin [23] and acrylic resin [24, 25].

The effect of MFC on the mechanical properties of composites has been previously studied. The strength and stiffness of a $16.5 \mathrm{wt} . \% \mathrm{MFC} /$ polyurethane composite was 
found to be greater than that of the pure polymer by factors of 5 and 30 respectively [22]. Similarly, Lu et al. [8] found that MFC reinforced PVA composites showed enhanced mechanical properties compared to the pure resin. The strength of MFC reinforced phenol formaldehyde resin composites was found to increase by $50 \%$ compared to the pure resin [23]. Suryanegara et al. [10] compared the tensile strength and Young's modulus of PLA reinforced with 10 wt.\% MFC with those of the pure PLA; although tensile strength increased by only about $10 \%$, the Young's modulus increased by almost $30 \%$. In part, these increases were also due to an increase in the degree of crystallinity of the composite, since MFC acts as a nucleating agent for crystal growth.

Raman spectroscopy has been used to better understand the interfaces between cellulose nanofibres and polymer matrices [4, 26, 27]. The position of a Raman band initially located at $\sim 1095 \mathrm{~cm}^{-1}$, corresponding to $\mathrm{C}-\mathrm{O}$ and $\mathrm{C}-\mathrm{C}$ stretching modes along the cellulose polymer backbone [28], has been monitored during tensile deformation. The stress-transfer mechanisms of polymers reinforced with MFC [4, 27], bacterial cellulose [26], cellulose nanowhiskers [29-31] have been previously reported.

The interfacial bonding between MFC and PVA should be good compared to hydrophobic matrices, since both materials exhibit hydrophilicity. In the present work MFC fibrils were prepared using combined homogeniser and sonicator treatments. PVA/MFC composites were then fabricated using a solvent casting method. We report also the use of Raman spectroscopy to investigate the stress-transfer process in the composites at the interface between the cellulose and the polymer. Although several studies of MFC reinforced PVA composites have been published, to the authors' knowledge, none study the stress transfer process in these composites using Raman spectroscopy. Further, whereas previous studies report results for native (cellulose-I) 
fibrils, here, we use cellulose-II fibrils extracted from lyocell, which has been shown to produce nanofibrils with a potential axial tensile modulus of $~ 90 \mathrm{GPa}$ [14].

\section{Experimental}

\section{Materials}

Chopped regenerated cellulose fibres of length of $\sim 10 \mathrm{~mm}$ produced using a draw ratio of 8.9 (trade name Tencel®), provided by Lenzing AG, Austria, were used as the raw material to prepare MFC fibrils. Poly(vinyl alcohol) (PVA) with an average molecular weight of $85,000-124,000 \mathrm{~g} \mathrm{~mol}^{-1}$, purchased from Sigma-Aldrich, was used as a matrix for the preparation of composites.

\section{MFC preparation}

Lyocell fibres were soaked in distilled water for $24 \mathrm{~h}$ before mechanical treatment. The suspension was mechanically treated using a homogeniser (ULTRA-TURRAX TP 18/2K, Janke \& Kunkel, Staufen) at 20,000 rpm for a range of times between 10 and 60 min, and then sonicated using a high intensity sonifier (BRANSON MODEL 250, 20 $\mathrm{kHz}$ ) at $200 \mathrm{~W}$ for $30 \mathrm{~min}$. The MFC suspension was poured into a Petri dish, and was subsequently kept in a controlled room at a temperature of $23 \pm 2{ }^{\circ} \mathrm{C}$ and relative humidity of $50 \pm 2 \%$ for at least a week until MFC networks were formed upon evaporation of the liquid phase. The networks were then dried in an oven at $50{ }^{\circ} \mathrm{C}$ for 7 days. The pure MFC network had a thickness of $\sim 110 \mu \mathrm{m}$. 


\section{Composite preparation}

MFC reinforced PVA composites were manufactured by first preparing a $10 \mathrm{wt} . \%$ solution of PVA in distilled water. Different weight fractions (1, 2, 3 and 4 wt.\%) of the fibrils obtained after a 30 min mechanical treatment were mixed into the PVA solution for $4 \mathrm{~h}$, and were subsequently sonicated for $10 \mathrm{~min}$ to optimise dispersion. These mixtures were poured into a Petri dish to cast into a film, and were kept in a controlled humidity and temperature room until the films had formed. These composite films were then fully dried in an oven at $50{ }^{\circ} \mathrm{C}$ for $6 \mathrm{~h}$. The thickness of the composite films measured using a micrometer was $\sim 170 \mu \mathrm{m}$.

\section{Thermogravimetric analysis}

The degradation temperature of MFC reinforced PVA composites, neat PVA and 60 min treated MFC was investigated using a NETZSCH Simultaneous thermogravimetic analysis (STA) 449C instrument. Samples with a mass of $5.0 \pm 0.5 \mathrm{mg}$ were placed in an aluminium crucible, and then were heated in the range $30-500{ }^{\circ} \mathrm{C}$ at $10{ }^{\circ} \mathrm{C} \mathrm{min}^{-1}$ under

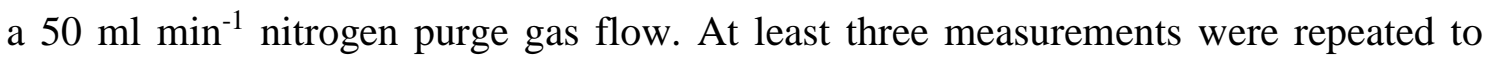
ensure reliability of the results.

\section{Mechanical testing}

Tensile properties of the PVA composites reinforced with MFC fibrils and neat PVA resin were measured using an Instron 1121 universal testing machine equipped with a $500 \mathrm{~N}$ 
load cell. Specimens with a gauge length of $10 \mathrm{~mm}$ and a width of $2 \mathrm{~mm}$ prepared using a razor blade were tested at a crosshead speed of $5 \mathrm{~mm} \mathrm{~min}^{-1}$. Before testing, all specimens were kept in a controlled room at $23 \pm 2{ }^{\circ} \mathrm{C}$ and $50 \pm 2 \%$ relative humidity for $48 \mathrm{~h}$. At least 7 samples were tested for each material.

\section{Raman spectroscopy}

Micromechanical deformation of the PVA composites reinforced with 4 wt.\% MFC and MFC networks were studied using a Renishaw system 1000 Raman spectrometer coupled to a $25 \mathrm{~mW} 785 \mathrm{~nm}$ near-infrared laser. A 50× objective lens and an Olympus microscope system were used to focus the laser on the samples' surfaces with a spot size $\sim 2 \mu \mathrm{m}$ and intensity of $\sim 1 \mathrm{~mW}$. The samples were deformed using a customised deformation rig equipped with a $2 \mathrm{kN}$ load cell (Deben Microtest, Deben, Bury St Edmonds, UK). Raman spectra were recorded in the range of $1050-1150 \mathrm{~cm}^{-1}$ using an exposure time of $50 \mathrm{~s}$ (consisting of an exposure time of $10 \mathrm{~s}$ and five accumulations) at strain increments of 0.1\%. A combined Gaussian/ Lorentzian distribution was used to determine the peak position of a Raman band initially located at $\sim 1095 \mathrm{~cm}^{-1}$ using a least-squares fitting method. At least three samples were tested for each set of materials.

\section{Results and Discussion}

Morphology of MFC fibrils 
Figure 1 shows $1 \%(\mathrm{w} / \mathrm{w})$ aqueous suspensions of lyocell fibres and MFC with different mechanical treatment times (10, 20, 30, 40, 50 and $60 \mathrm{~min})$. No appreciable sedimentation can be observed for MFC fibrils, even after 24 hours. This lack of sedimentation is due to an increase of the degree of fibrillation, an increase in the aspect ratio and the surface area of MFC fibrils. Our observations are consistent with those of Martinez et al. [32], who studied the effect of fibre dimensions on the sedimentation of cellulosic fibres. They observed a 'critical' sedimentation concentration', at which a 3D fibre network capable of supporting a load was formed. This concentration was found to depend on the aspect ratio of the fibres, such that fibres of high aspect ratio exhibit a lower critical concentration than those of low aspect ratio. We note that the number of contacts per fibre in a 3D random network, which we expect to influence network strength, is proportional to the fibre aspect ratio [33]. A higher degree of fibrillation with an expected increase in the surface area of the fibrils was also observed when the ultrasonic output power increased, as previously reported [34].

Intact lyocell fibres typically exhibit highly uniform circular cross-sections with diameters $\sim 10 \mu \mathrm{m}$, as has been reported previously [35]. Images of fibrils after mechanical treatments of intact fibres for durations between 10 and $60 \mathrm{~min}$ are shown in Figure 2. After mechanical treatment, MFC fibrils were readily fibrillated from the intact fibres. This is due to the fact that when lyocell fibres, a highly oriented crystalline material, are under mechanical stress in a wet condition, the intra-hydrogen bonds between cellulose chains in the crystalline regions are easily broken. This allows fibrillation to occur, a well-known phenomenon for lyocell [36-39]. Therefore, as the treatment time used to fibrillate the lyocell fibres increases, the fraction of fibrils with diameter less than $500 \mathrm{~nm}$ increases [40, 41]. 
When lyocell fibres with initial diameter $\sim 10 \mu \mathrm{m}$ were mechanically treated for $10 \mathrm{~min}$, fibrils with mean diameter $\sim 450 \mathrm{~nm}$ were generated; the mean fibril diameter reduced to $\sim 365 \mathrm{~nm}$ after $30 \mathrm{~min}$ mechanical treatment; thereafter, no significant change in the average diameter of MFC or its coefficient of variation was observed, as shown in Figure

3. This suggests that this is the ultimate fibrillar sub-structure that can be achieved using this approach, though we would anticipate exposure of the suspension to higher shear would result in further attrition, reducing the mean fibril diameter [41]. Ultimately, we would anticipate that above some threshold shear level, there would be no further attrition and fibrils would exhibit a minimum diameter depending on the size of the crystalline regions within the fibril. Given our results, MFC fibrils produced using a treatment time of 30 min were selected to prepare composites.

\section{Thermogravimetric analysis}

Thermogravimetric analysis curves of the MFC reinforced PVA composites compared to neat PVA and MFC fibrils are shown in Figure 4, and a summary of the degradation temperatures of the MFC reinforced PVA composites compared to neat PVA and MFC fibrils is reported in Table 1 . The weight of MFC fibrils reduces by up to $100{ }^{\circ} \mathrm{C}$ due to the evaporation of moisture [34]. The degradation temperatures of neat PVA and MFC fibrils are $252{ }^{\circ} \mathrm{C}$ and $303{ }^{\circ} \mathrm{C}$ respectively. The addition of MFC in the PVA resin clearly increases the degradation temperature, which gives clear benefit over using other forms of nanocellulose (cellulose nanocrystals) which have been reported to have limited thermal stability [42]. It is noted that the thermal decomposition of cellulose-reinforced composites depends on the content and the thermal stability of the cellulose $[42,43]$. In the case of cellulose nanocrystals it is heavily dependent on the presence of sulphate ester groups [42]. 


\section{Mechanical properties}

The mechanical properties of neat PVA films and MFC reinforced PVA composites are reported in Figure 5. The addition of MFC increases the tensile strength and Young's modulus of the composites above those of neat PVA. This indicates a reinforcement of the relatively compliant PVA matrix by the stiffer and stronger cellulose microfibrils. The tensile strength and modulus of the $3 \mathrm{wt} . \%$ MFC reinforced PVA composites are higher than those of neat PVA resin by $\sim 13 \%$ and $\sim 34 \%$ respectively. Slightly smaller increases of $3 \%$ and $15 \%$ for tensile strength and modulus of PVA composites reinforced with 2 wt.\% MFC have been previously reported [20]. For the present samples, when the addition of MFC is greater than 3 wt.\%. no further increases in the tensile strength and Young's modulus of the composites are observed. This may be due to the formation of fibril aggregates, which reduces the effective aspect ratio, consistent with previous observations [20], though further analysis would be required to confirm this hypothesis. The rule of mixtures for a fibre reinforced composite can be written in the following form

$$
E_{\mathrm{c}}=\eta_{\mathrm{f}} \eta_{1} V_{\mathrm{f}} E_{\mathrm{f}}+\left(1-V_{\mathrm{f}}\right) E_{\mathrm{m}}
$$

where $E_{\mathrm{c}}, E_{\mathrm{f}}$ and $E_{\mathrm{m}}$ are the moduli of the composite, the fibre component and the matrix respectively. Two efficiency factors are included in Eqn. $1 ; \eta_{\mathrm{f}}$ is fibre efficiency factor which for an in-plane random network of fibres is $3 / 8$ [44], and $\eta_{1}$ is the fibre length efficiency factor, which for continuous fibres can be considered to be $\sim 1$. The electron micrographs in Figure 2 suggest a 2D 'planar' random fibrous network which we expect to be preserved during processing. Previously we have found that networks of celluose nanofibres can be treated like a continuous phase with $\eta_{1} \sim 1$ [45]. Now, $E_{\mathrm{m}}$ $=1.2 \pm 0.1 \mathrm{GPa}$ and we see significant reinforcement $\left(E_{\mathrm{c}}=1.6 \pm 0.2 \mathrm{GPa}\right)$ when $V_{\mathrm{f}}=$ 
0.03. Substituting these values into Equation 1 yields an estimate of the modulus of a single fibril $E_{\mathrm{f}} \approx 39 \mathrm{GPa}$. This compares to a reported modulus of a single fibril extracted from a lyocell fibre of $\sim 90 \mathrm{GPa}[14]$. Although the modulus for our material is lower than this independent measurement, they are similar to those obtained for microfibrillated cellulose obtained from wood, where values in the range $26-36 \mathrm{GPa}$ have been reported [15]. It may be that the interface between the PVA and the fibrils is not that strong, and so this estimate is low because of a lack of stress transfer. Also we may have introduced some defects into the materials during processing. We note that Cheng and Wang [14] also used a high intensity treatment to evolve their materials, yielding more slender fibrils of diameter $\sim 170 \mathrm{~nm}, c f$. our value of $\sim 300 \mathrm{~nm}$. Of course modulus intrinsically should not necessarily depend on the thickness of the fibrils, but recent work on electrospun polymer fibres does show a pronounced effect of fibre thickness on modulus [46,47]. So a smaller diameter could yield a higher modulus. Our values for the predicted moduli of the fibrils do exceed those obtained for the same batch of micron-sized fibres ( 26 GPa) [48] which suggests that some reduction in the lateral size of the fibres results in an increase in the modulus. This increase in modulus could occur due to the inherent lateral crystal dimension becoming more significant at smaller fibre diameters.

\section{Raman spectroscopy}

Typical Raman spectra obtained from a neat PVA film, a PVA composite reinforced with 4 wt.\% MFC (only the peak obtained from the PVA composite reinforced with 4 wt.\% MFC was intense enough to be investigated) and MFC fibrils, where the Raman peak 
initially located at $\sim 1095 \mathrm{~cm}^{-1}$ is highlighted, are shown in Figure 6 . The peak initially located at $\sim 1095 \mathrm{~cm}^{-1}$ corresponding to the C-O stretching mode [28] and possibly the CO-C glycosidic bond stretching mode [49] obtained from the PVA composite reinforced with 4 wt.\% MFC was used to monitor stress-transfer in the composites. No peak at 1095 $\mathrm{cm}^{-1}$ is observed from the neat PVA. It is therefore possible to follow a shift in the peak located at $\sim 1095 \mathrm{~cm}^{-1}$ and therefore to detect stress transfer mechanisms in the composite.

A typical shift in the position of the Raman band initially located at $\sim 1095 \mathrm{~cm}^{-1}$ upon tensile deformation for the PVA composite reinforced with 4 wt.\% MFC is shown in Figure 7. This shift in the peak position occurs due to the direct deformation of the cellulose molecular backbone [4, 26, 27].

Figure 8 shows the shift in the position of the Raman band initially located at $\sim 1095 \mathrm{~cm}^{-}$ ${ }^{1}$ with respect to tensile strain for the MFC network and for the $4 \mathrm{wt} . \%$ MFC reinforced composite. A greater shift rate as a function of strain was observed for the 4 wt.\% MFC reinforced composites $\left(-0.44 \pm 0.02 \mathrm{~cm}^{-1} \%{ }^{-1}\right)$, compared to the pure MFC networks ($\left.0.34 \pm 0.06 \mathrm{~cm}^{-1} \%{ }^{-1}\right)$. This difference can be attributed to stress transfer from the matrix to the stiffer MFC fibrils. A significant change in the direction of the shift in the position of the Raman band initially located at $\sim 1095 \mathrm{~cm}^{-1}$ for the 4 wt.\% MFC reinforced PVA composite can be observed $>3 \%$ strain. This is thought to be due to debonding of MFC fibrils from the matrix. Stress transfer still occurs in the pure MFC networks due to interactions between the fibrils via hydrogen bonding. Therefore, in the composite materials it is thought that stress-transfer is a combination of matrix-fibril and fibril-fibril interactions.

\section{Conclusions}


A combination between homogenization and sonication methods was successfully used to prepare MFC fibrils in the range of $350-500 \mathrm{~nm}$ from lyocell fibres with an initial diameter $\sim 10 \mu \mathrm{m}$. After a fibrillation time of 30 minutes no further significant reduction in the fibril diameter was noted. MFC reinforced PVA composites were successfully prepared using fibrils produced using a fibrillation time of 30 minutes. Mechanical properties (tensile strength and Young's modulus) of MFC reinforced PVA composites increase as the weight fraction of MFC in the composites is increased, compared to neat PVA films. This increase is attributed to stress transfer between the matrix and the MFC fibrils and a prediction of $\sim 39 \mathrm{GPa}$ for the fibril modulus is inferred via the rule of mixtures. Raman spectroscopy was successfully used to monitor the stress-transfer mechanisms in the MFC reinforced PVA composites. A greater shift rate with respect to strain for the Raman band initially located at $\sim 1095 \mathrm{~cm}^{-1}$ was observed from 4 wt.\% MFC/PVA composites compared to pure MFC networks, indicating the stress-transfer from the matrix to MFC fibrils.

\section{Acknowledgement}

The authors thank Lenzing AG, Austria, for kindly providing lyocell fibres.S. Tanpichai thanks the Royal Thai Government for financial support. 


\section{References}

[1] Herrick FW, Casebier RL, Hamilton JK, Sandberg KR. Microfibrillated cellulose: morphology and accessibility. J Appl Polym Sci: Appl Polym Symp. 1983;37:797-813.

[2] Turbak AF, Snyder FW, Sandberg KR. Microfibrillated cellulose, a new cellulose product: Properties, uses, and commercial potential. J Appl Polym Sci: Appl Polym Symp. 1983;37:815-827.

[3] Siro I, Plackett D. Microfibrillated cellulose and new nanocomposite materials: A review. Cellulose. 2010;17(3):459-494.

[4] Tanpichai S, Sampson WW, Eichhorn SJ. Stress-transfer in microfibrillated cellulose reinforced poly(lactic acid) composites using Raman spectroscopy. Compos Pt A-Appl Sci Manuf. 2012;43(7):1145-1152.

[5] Aulin C, Gallstedt M, Lindstrom T. Oxygen and oil barrier properties of microfibrillated cellulose films and coatings. Cellulose. 2010;17(3):559-574.

[6] Henriksson M, Henriksson G, Berglund LA, Lindstrom T. An environmentally friendly method for enzyme-assisted preparation of microfibrillated cellulose (MFC) nanofibers. Eur Polym J. 2007;43(8):3434-3441.

[7] Iwatake A, Nogi M, Yano H. Cellulose nanofiber-reinforced polylactic acid. Compos Sci Technol. 2008;68(9):2103-2106.

[8] Lu J, Wang T, Drzal LT. Preparation and properties of microfibrillated cellulose polyvinyl alcohol composite materials. Compos Pt A-Appl Sci Manuf. 2008;39(5):738746.

[9] Nakagaito AN, Fujimura A, Sakai T, Hama Y, Yano H. Production of microfibrillated cellulose (MFC)-reinforced polylactic acid (PLA) nanocomposites from sheets obtained by a papermaking-like process. Compos Sci Technol. 2009;69(7-8):1293-1297.

[10] Suryanegara L, Nakagaito AN, Yano H. Thermo-mechanical properties of microfibrillated cellulose-reinforced partially crystallized PLA composites. Cellulose. 2010;17(4):771-778.

[11] Sakurada I, Nukushina Y, Ito T. Experimental determination of elastic modulus of crystalline regions in oriented polymers. J Polym Sci. 1962;57(165):651-660.

[12] Nishino T, Takano K, Nakamae K. Elastic-modulus of the crystalline regions of cellulose polymorphs. J Polym Sci Pt B-Polym Phys. 1995;33(11):1647-1651.

[13] Sturcova A, Davies GR, Eichhorn SJ. Elastic modulus and stress-transfer properties of tunicate cellulose whiskers. Biomacromol. 2005;6(2):1055-1061.

[14] Cheng QZ, Wang SQ. A method for testing the elastic modulus of single cellulose fibrils via atomic force microscopy. Compos Pt A-Appl Sci Manuf. 2008;39(12):18381843. 
[15] Tanpichai S, Quero F, Nogi M, Yano H, Young RJ, Lindström T, et al. Effective Young's Modulus of Bacterial and Microfibrillated Cellulose Fibrils in Fibrous Networks. Biomacromol. 2012;13(5):1340-1349.

[16] Guhados G, Wan WK, Hutter JL. Measurement of the elastic modulus of single bacterial cellulose fibers using atomic force microscopy. Langmuir. 2005;21(14):66426646.

[17] Hsieh YC, Yano H, Nogi M, Eichhorn SJ. An estimation of the Young's modulus of bacterial cellulose filaments. Cellulose. 2008;15(4):507-513.

[18] Iwamoto S, Kai WH, Isogai A, Iwata T. Elastic Modulus of Single Cellulose Microfibrils from Tunicate Measured by Atomic Force Microscopy. Biomacromol. 2009;10(9):2571-2576.

[19] Josefsson G, Tanem BS, Li Y, Vullum PE, Gamstedt EK. Prediction of elastic properties of nanofibrillated cellulose from micromechanical modeling and nanostructure characterization by transmission electron microscopy. Cellulose. 2013;20(2):761-770.

[20] Cheng Q, Wang SQ, Rials TG, Lee SH. Physical and mechanical properties of polyvinyl alcohol and polypropylene composite materials reinforced with fibril aggregates isolated from regenerated cellulose fibers. Cellulose. 2007;14(6):593-602.

[21] Cheng QZ, Wang SQ, Rials TG. Poly(vinyl alcohol) nanocomposites reinforced with cellulose fibrils isolated by high intensity ultrasonication. Compos Pt A-Appl Sci Manuf. 2009;40(2):218-224.

[22] Seydibeyoglu MO, Oksman K. Novel nanocomposites based on polyurethane and micro fibrillated cellulose. Compos Sci Technol. 2008;68(3-4):908-914.

[23] Nakagaito AN, Yano $H$. The effect of morphological changes from pulp fiber towards nano-scale fibrillated cellulose on the mechanical properties of high-strength plant fiber based composites. Appl Phys A-Mater Sci Process. 2004;78(4):547-552.

[24] Iwamoto S, Nakagaito AN, Yano H, Nogi M. Optically transparent composites reinforced with plant fiber-based nanofibers. Appl Phys A-Mater Sci Process. 2005;81(6):1109-1112.

[25] Iwamoto S, Nakagaito AN, Yano H. Nano-fibrillation of pulp fibers for the processing of transparent nanocomposites. Appl Phys A-Mater Sci Process. 2007;89(2):461-466.

[26] Quero F, Nogi M, Yano H, Abdulsalami K, Holmes SM, Sakakini BH, et al. Optimization of the mechanical performance of bacterial cellulose/poly(L-lactic) acid composites. ACS Appl Mater Interf. 2010;2(1):321-330.

[27] Bulota M, Tanpichai S, Hughes M, Eichhorn SJ. Micromechanics of TEMPOoxidized fibrillated cellulose composites. ACS Appl Mater Interf. 2012;4(1):331-337.

[28] Wiley JH, Atalla RH. Band assignments in the Raman-spectra of celluloses. Carbohydrate Research. 1987;160:113-29. 
[29] Rusli R. Interfacial micromechanics of natural cellulose whisker polymer nanocomposites using Raman spectroscopy PhD Thesis. The University of Manchester, School of Materials, 2011.

[30] Rusli R, Eichhorn SJ. Determination of the stiffness of cellulose nanowhiskers and the fiber-matrix interface in a nanocomposite using Raman spectroscopy. Appl Phys Lett. 2008;93(3):033111.

[31] Rusli R, Shanmuganathan K, Rowan SJ, Weder C, Eichhorn SJ. Stress-transfer in anisotropic and environmentally adaptive cellulose whisker nanocomposites. Biomacromol. 2010;11(3):762-768.

[32] Martinez DM, Buckley K, Jivan S, Lindstrom A, Thiruvengadaswamy R, Olson JA, Ruth TJ, Kerekes RJ. Characterizing the mobility of papermaking fibres during sedimentation. In: Baker CF (ed) The science of papermaking. Transactions of the 12th Fundamental Research Symposium, Oxford. (2001) The Pulp and Paper Fundamental Research Society, Bury, Lancashire, UK, 225-254.

[33] Dodson CTJ. Fiber crowding, fiber contacts, and fiber flocculation. Tappi Journal. 1996;79(9):211-6.

[34] Chen WS, Yu HP, Liu YX, Chen P, Zhang MX, Hai YF. Individualization of cellulose nanofibers from wood using high-intensity ultrasonication combined with chemical pretreatments. Carbohydr Polym. 2011;83(4):1804-1811.

[35] Mottershead B, Eichhorn SJ. Deformation micromechanics of model regenerated cellulose fibre-epoxy/polyester composites. Composites Science and Technology. 2007;67(10):2150-9.

[36] Lenz J, Schurz J, Wrentschur E. Properties and structure of solvent-spun and viscosetype fibers in the swollen state. Colloid Polym Sci. 1993;271(5):460-468.

[37] Nicolai M, Nechwatal A, Mieck KP. Textile crosslinking reactions to reduce the fibrillation tendency of Lyocell fibers. Text Res J. 1996;66(9):575-580.

[38] Udomkichdecha W, Chiarakorn S, Potiyaraj P. Relationships between fibrillation behavior of Lyocell fibers and their physical properties. Text Res J. 2002;72(11):939943.

[39] Chaudemanche C, Navard P. Swelling and dissolution mechanisms of regenerated lyocell cellulose fibers. Cellulose. 2011;18(1):1-15.

[40] Cheng Q, Wang SQ, Han QY. Novel process for isolating fibrils from cellulose fibers by high-intensity ultrasonication. II. Fibril characterization. J Appl Polym Sci. 2010;115(5):2756-2762.

[41] Chakraborty A, Sain MM, Kortschot MT, Ghosh SB. Modeling Energy Consumption for the Generation of Microfibres from Bleached Kraft Pulp Fibres in a PFI Mill. Bioresources. 2007;2(2):210-222.

[42] Wang N, Ding E, Cheng R. Thermal degradation behaviors of spherical cellulose nanocrystals with sulfate groups. Polymer. 2007;48(12):3486-3493. 
[43] Tome LC, Pinto RJB, Trovatti E, Freire CSR, Silvestre AJD, Neto CP, et al. Transparent bionanocomposites with improved properties prepared from acetylated bacterial cellulose and poly(lactic acid) through a simple approach. Green Chem. 2011;13(2):419-427.

[44] Krenchel H. Fibre reinforcement. Academisk Forlag: Copenhagen, 1964.

[45] Pullawan T, Wilkinson AN, Eichhorn SJ. Influence of Magnetic Field Alignment of Cellulose Whiskers on the Mechanics of All-Cellulose Nanocomposites. Biomacromol. 2012; 13(8) 2528-2536.

[46] Liu Y, Chen S, Zussman E, Korach CS, Zhao W, Rafailovich M. DiameterDependent modulus and melting behavior in electrospun semicrystalline polymer fibres. Macromol. 2011; 44(11):4439-4444.

[47] Stachewicz U, Bailey RJ, Wang W, Barber AH. Size depdendent mechanical properties of electrospun polymer fibers from a composite structure. Polymer 2012; 53(22): 5132-5137.

[48] Kong K, Eichhorn SJ. Crystalline and amorphous deformation of process-controlled cellulose-II fibres. Polymer 2005; 46(17): 6380-6390.

[49] Gierlinger N, Schwanninger M, Reinecke A, Burgert I. Molecular changes during tensile deformation of single wood fibers followed by Raman microscopy. Biomacromol. 2006;7(7):2077-2081. 


\section{FIGURE CAPTIONS}

Figure 1 Aqueous suspensions of lyocell fibres (0 min) and MFC fibrils after mechanical treatment for specific times (10-60 min).

Figure 2 Typical SEM micrographs of MFC fibrils produced by mechanical treatment of lyocell fibres for treatments up to 60 min duration.

Figure 3 Mean fibre diameters of MFC fibrils plotted against mechanical treatment time. Error bars are standard deviations from the mean; dotted line is illustrative only.

Figure 4 Thermogravimetric analysis curves of neat PVA, MFC reinforced composites and MFC fibrils.

Figure 5 (a) Tensile strength and (b) Young's modulus for neat PVA films (0 wt.\%) and PVA composites reinforced with MFC at volume fractions $1-4 \%$. Errors reported are standard deviations from the mean. Data labelled with a unique letter are significantly different $(\mathrm{P}<0.05)$ according to a $\mathrm{T}$ test.

Figure 6 Typical Raman spectra for the neat PVA film, a PVA composite reinforced with 4 wt.\% MFC and MFC fibrils. The position of the band located at $\sim 1095 \mathrm{~cm}^{-1}$ is marked (dotted line).

Figure 7 A typical shift in the position of the Raman band peak initially located at $\sim 1095 \mathrm{~cm}^{-1}$ for the PVA composite reinforced with $4 \mathrm{wt} . \%$ MFC deformed in tension from 0 to $2 \%$ strain.

Figure 8 Typical shifts in the peak position of the Raman band initially located at $\sim 1095 \mathrm{~cm}^{-1}$ as a function of strain for the composites of PVA and $4 \mathrm{wt} . \%$ MFC compared to data obtained from pure MFC networks. Solid lines are 
linear regressions to the data; MFC: Gradient $=-0.34 \pm 0.06 \mathrm{~cm}^{-1} \%{ }^{-1}, \mathrm{R}^{2}$ $=0.99$ and MFC/PVA composite: Gradient $=-0.44 \pm 0.02 \mathrm{~cm}^{-1} \%{ }^{-1}, \mathrm{R}^{2}=$ 0.99. The point at which debonding is thought to occur is indicated. 


\section{TABLE CAPTIONS}

Table 1 The degradation temperatures of MFC reinforced PVA composites and MFC fibrils. 


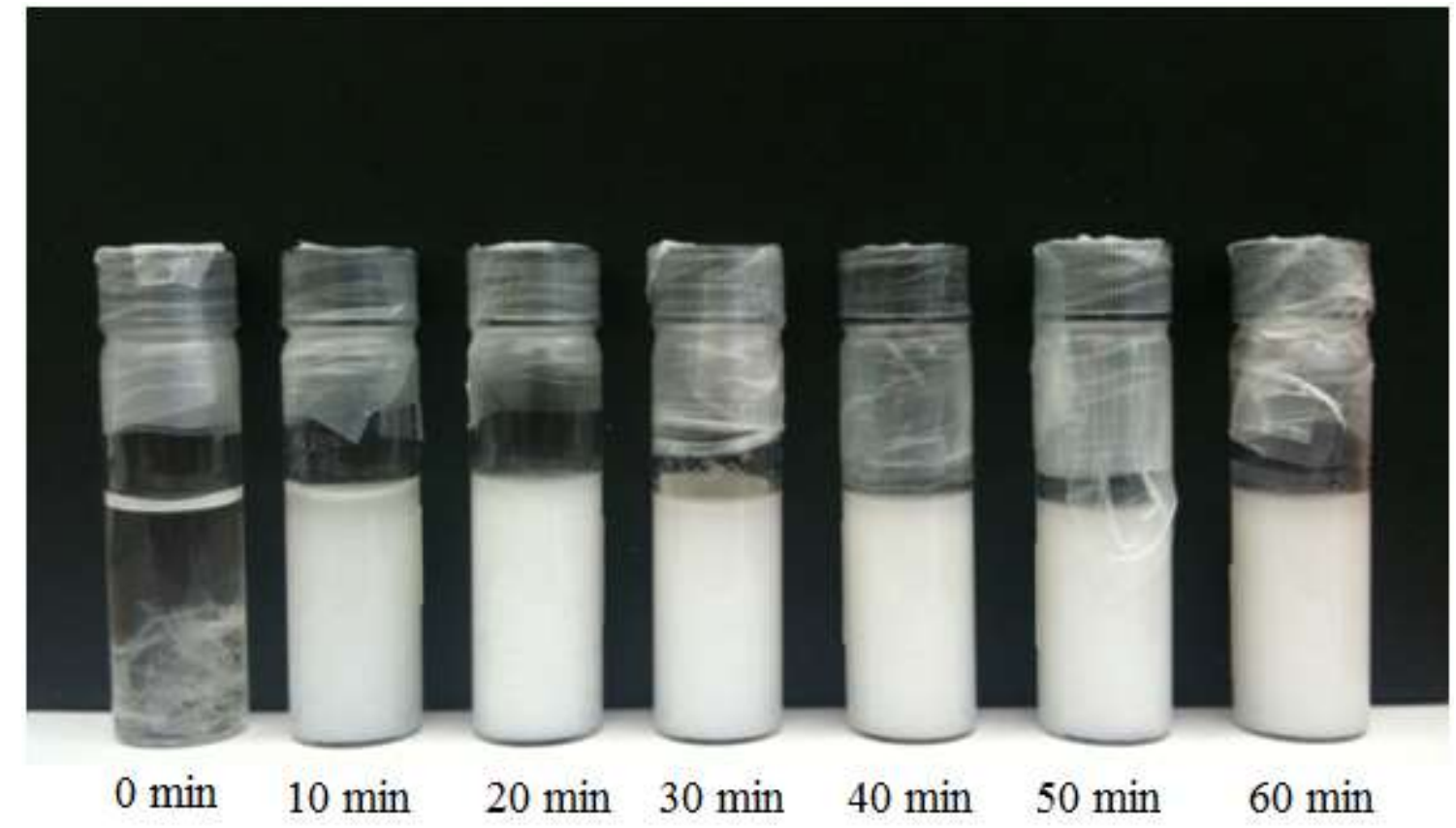

Figure 1 

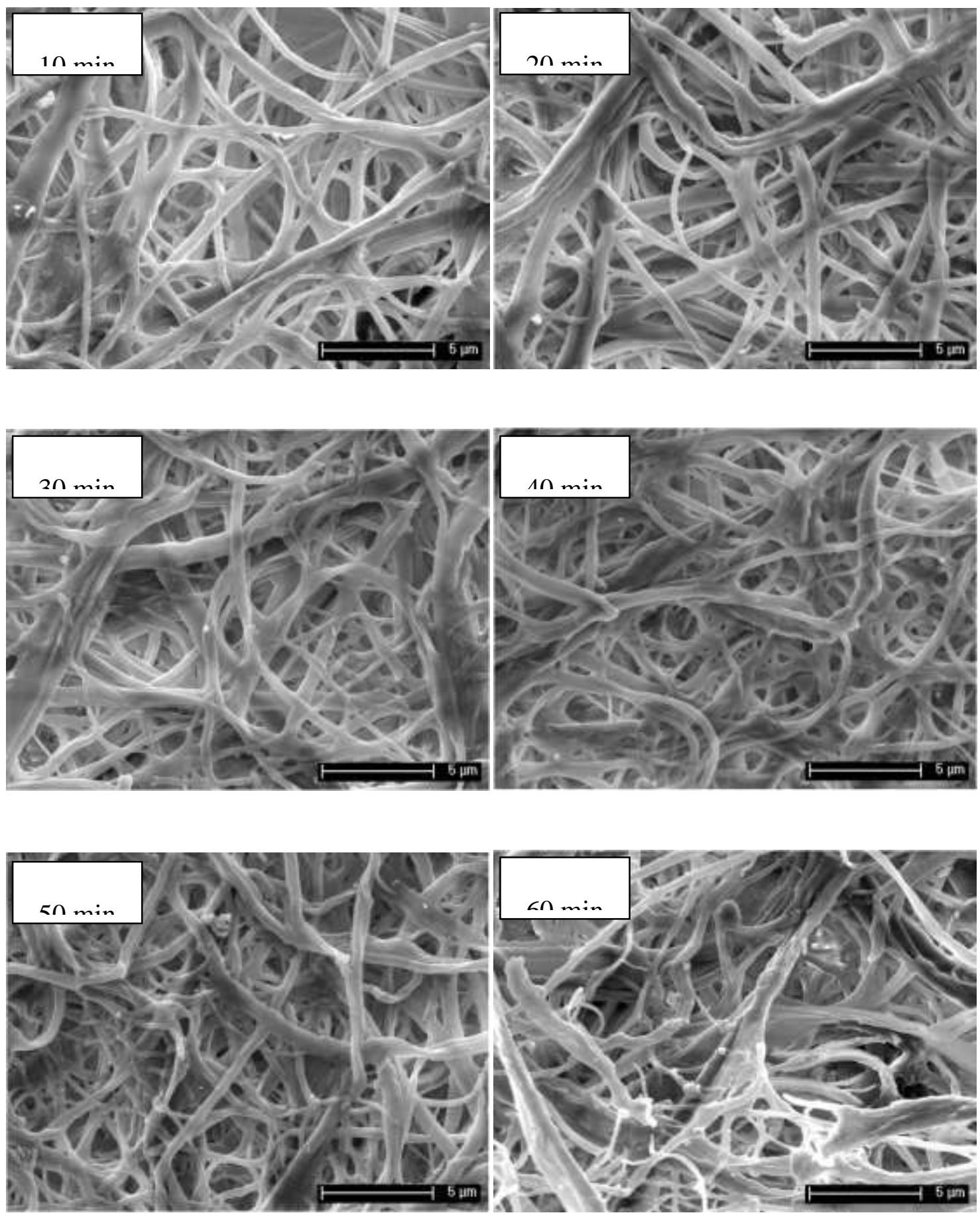

Figure 2 


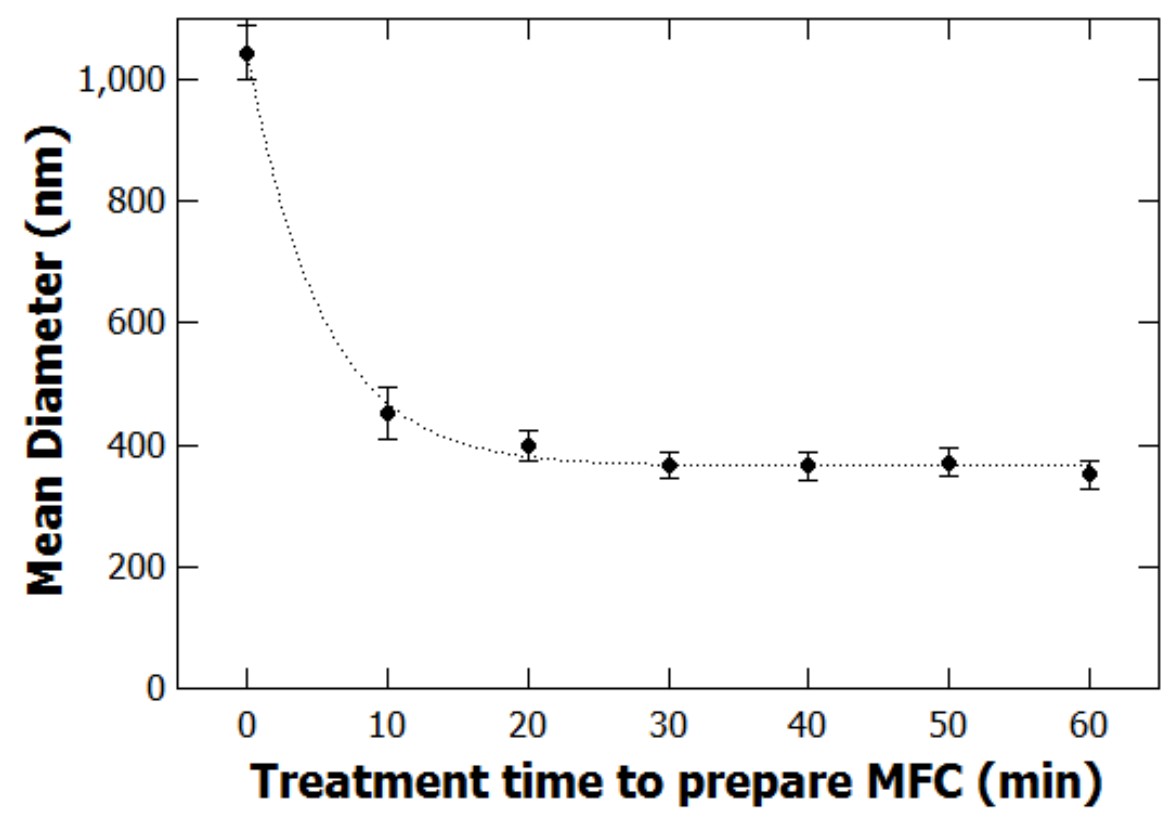

Figure 3 


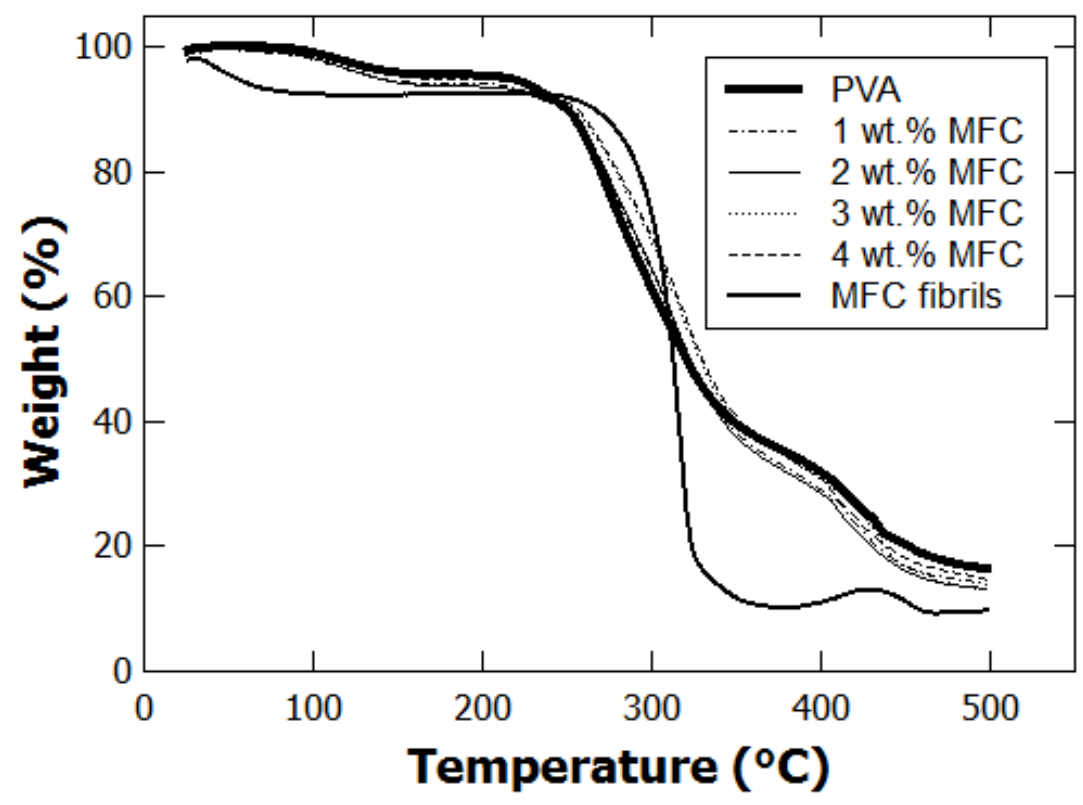

Figure 4 
(a)

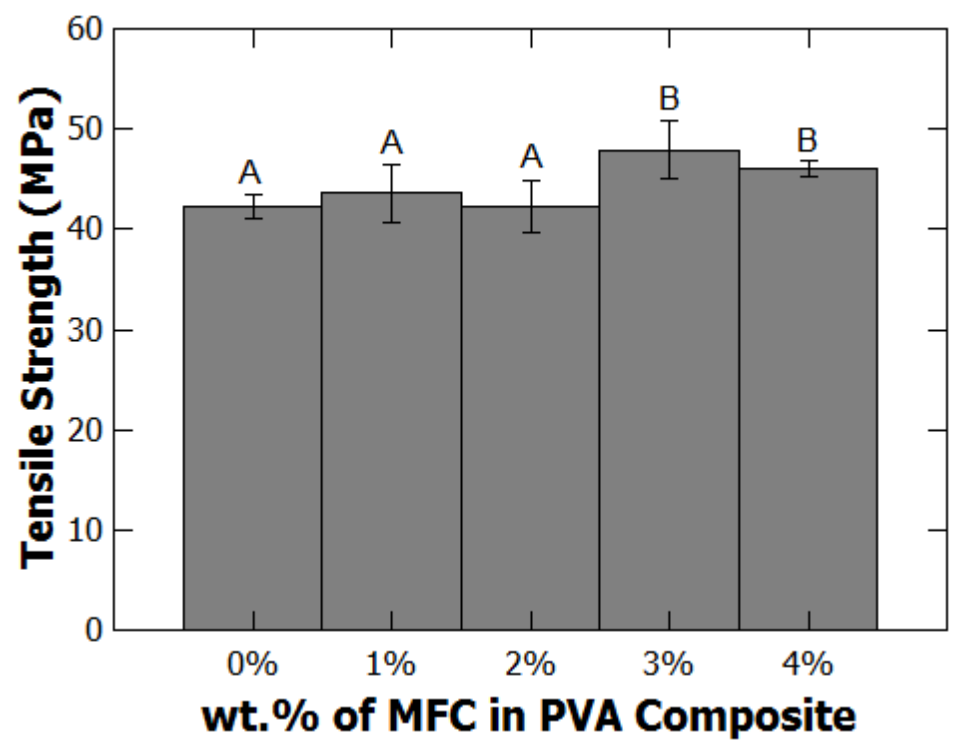

(b)

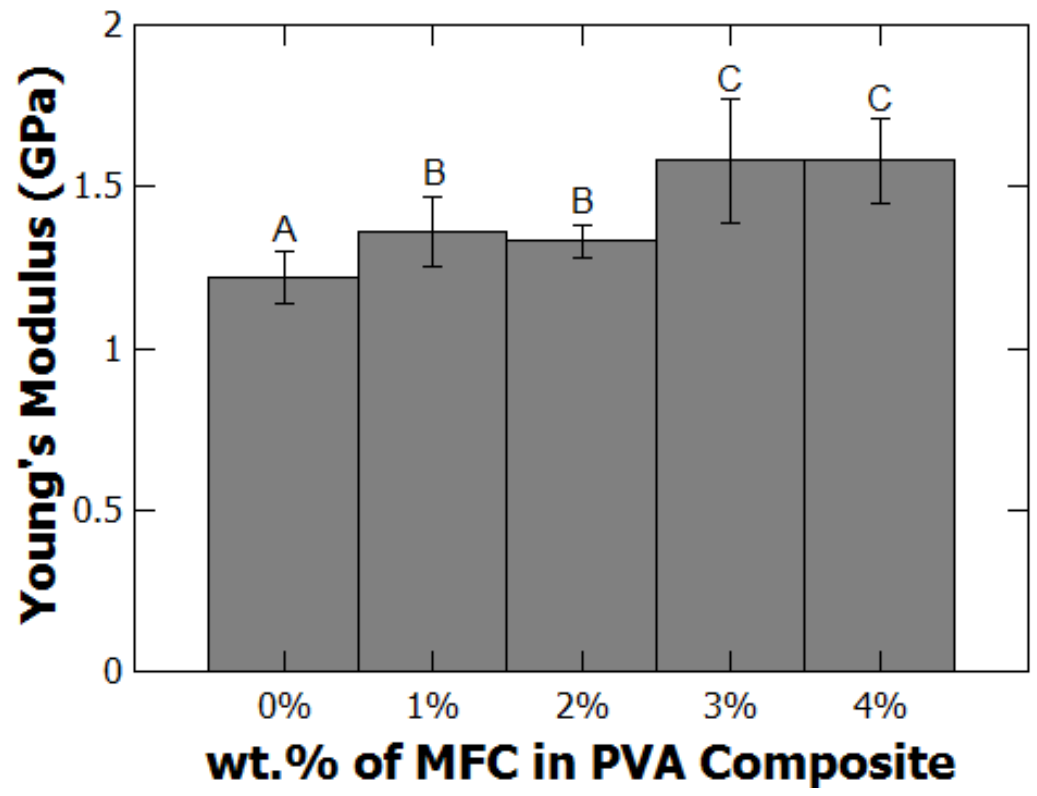

Figure 5 


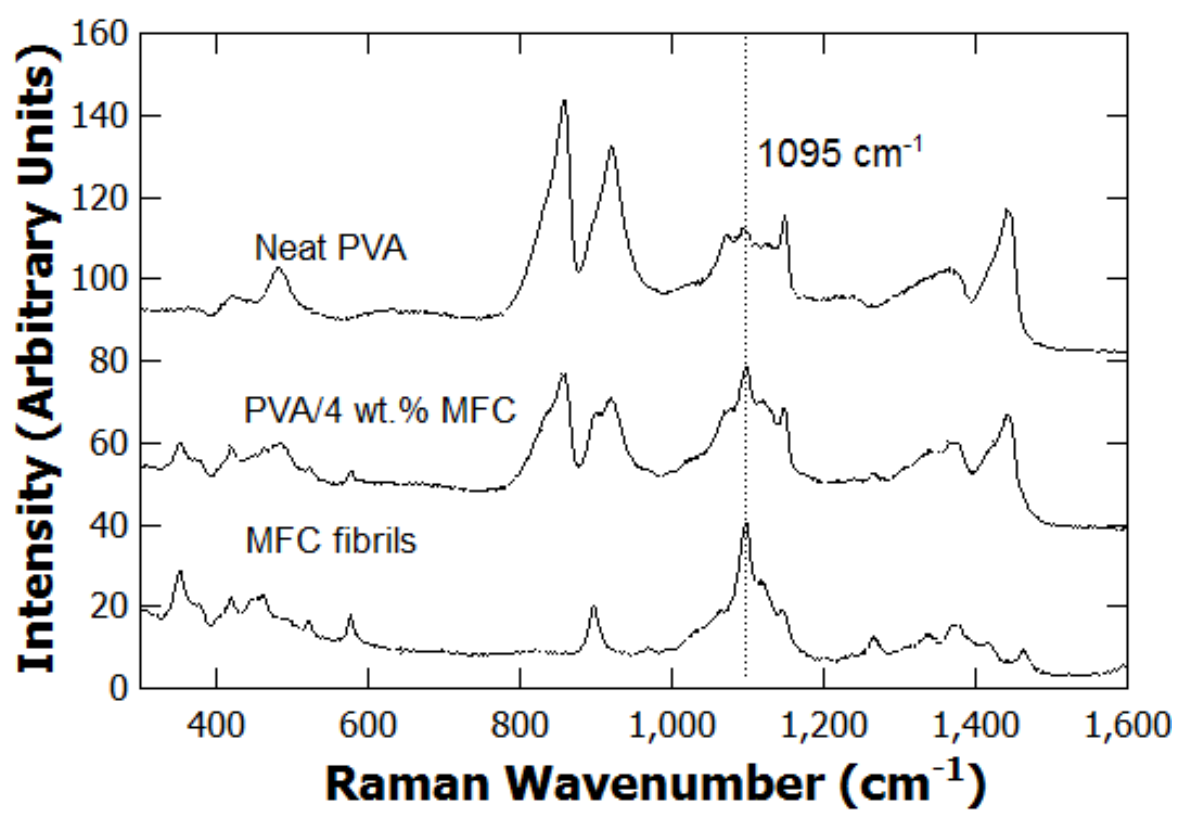

Figure 6 


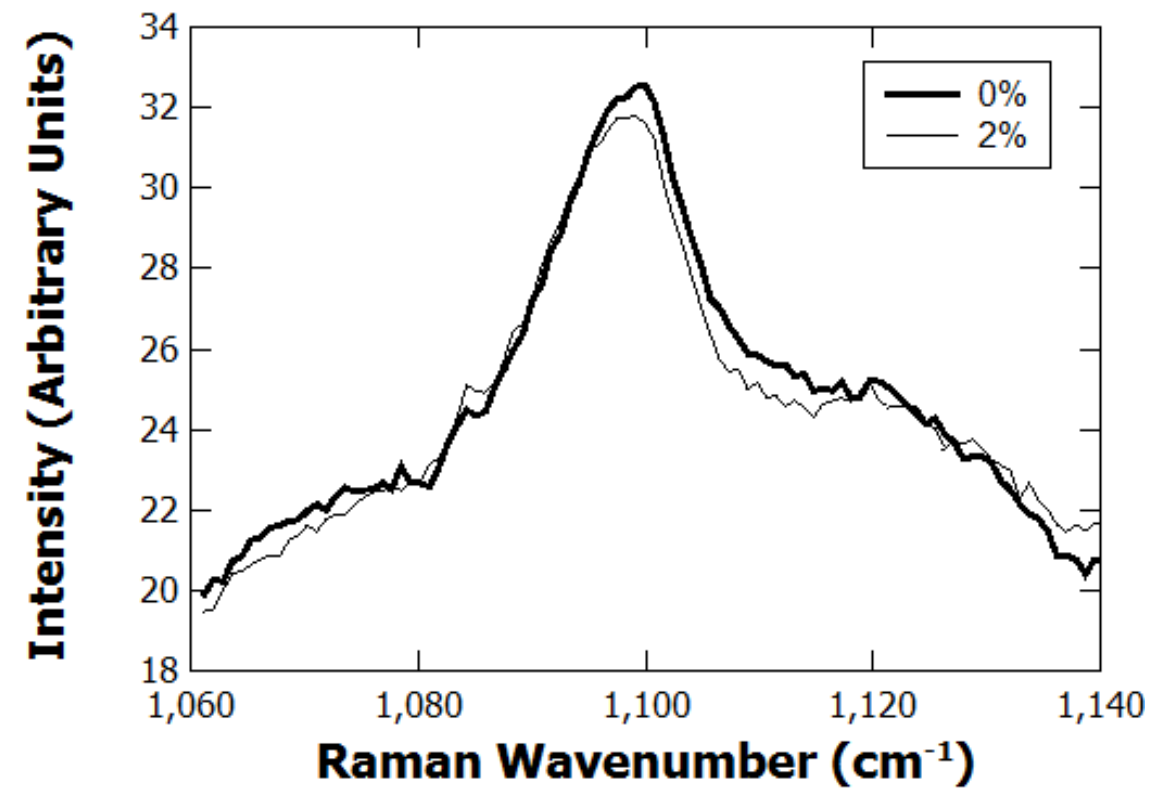

Figure 7 


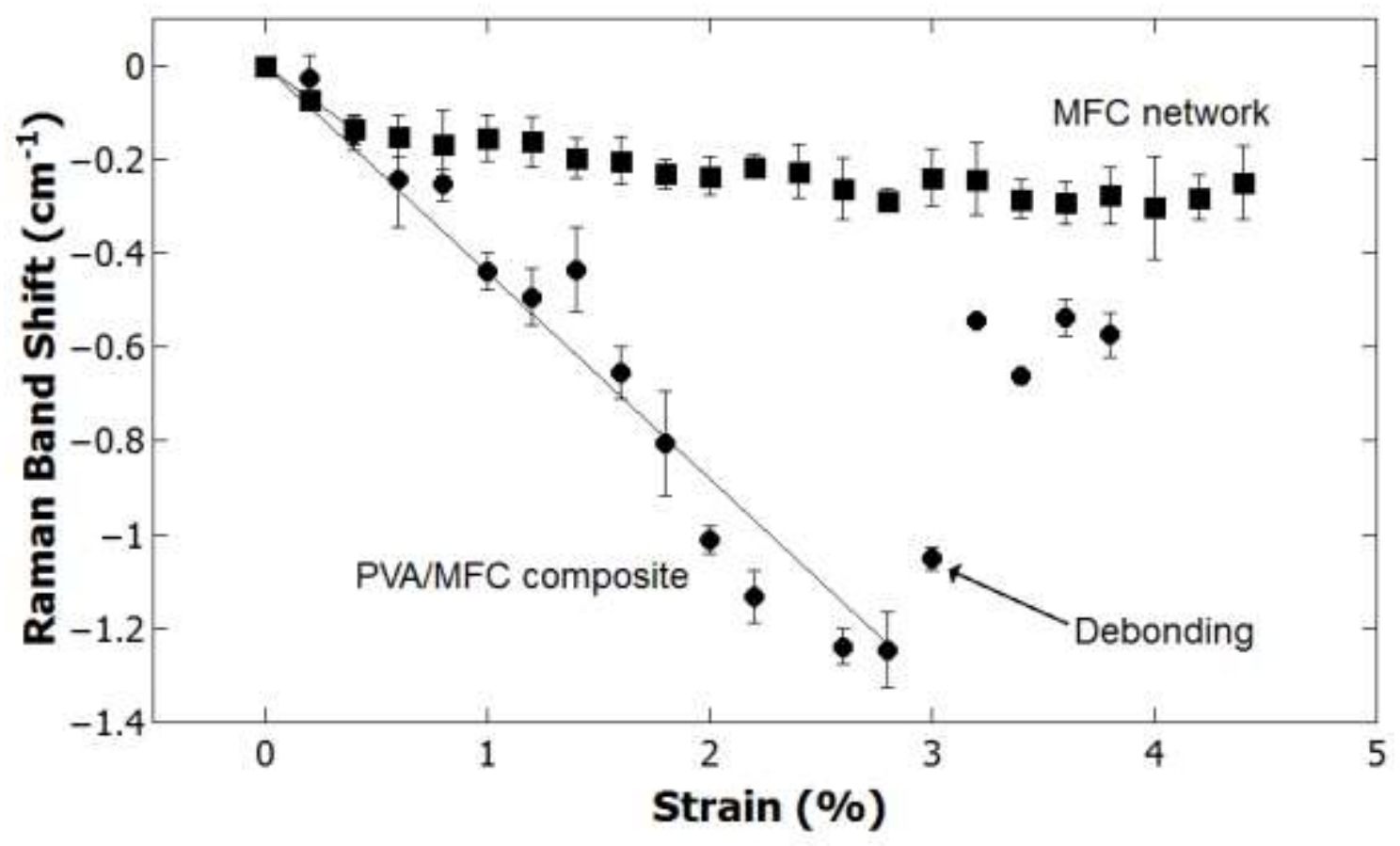

Figure 8 
Table 1

\begin{tabular}{|c|c|c|}
\hline \multicolumn{2}{|c|}{ Materials } & $\begin{array}{c}\text { Degradation Temperature } \\
\left({ }^{\circ} \mathrm{C}\right)\end{array}$ \\
\cline { 1 - 2 } PVA & MFC & 252 \\
\hline $100 \%$ & $0 \%$ & 255 \\
\hline $99 \%$ & $1 \%$ & 258 \\
\hline $98 \%$ & $2 \%$ & 265 \\
\hline $97 \%$ & $3 \%$ & 267 \\
\hline $96 \%$ & $4 \%$ & 303 \\
\hline $0 \%$ & $100 \%$ & \\
\hline
\end{tabular}

